\title{
Blue light dosage affects photosynthesis, chlorophyll, and antioxidant properties of Mesembryanthemum crystallinum
}

\author{
H. ZHANG*, Y. TU*, J. KANG*, W. SONG ${ }^{* * * *}$, and L. ZHENG ${ }^{*, * *+}$ \\ College of Water Resources and Civil Engineering, Qinghua East Road 17, 100083 Beijing, China* \\ Key Laboratory of Agricultural Engineering in Structure and Environment, Ministry of Agriculture and Rural \\ Affairs, Qinghua East Road 17, 100083 Beijing, China**
}

\begin{abstract}
Mesembryanthemum crystallinum is an annual succulent plant that is being used as an emerging healthy leafy vegetable. To investigate the growth and physiological response of $M$. crystallinum to artificial lighting, five different light treatments were applied at $150 \mu \mathrm{mol}$ (photon) $\mathrm{m}^{-2} \mathrm{~s}^{-1}$, which were white $(\mathrm{W})$, different rations of red/blue (B) (15, 40 , and $70 \% \mathrm{~B})$, and blue $(100 \% \mathrm{~B})$, respectively. Our results showed that plants could gain as much as edible leaf area and dry mass with a certain ratio of blue $(40 \%)$ in comparison with $\mathrm{W}$. Plants grown under $100 \% \mathrm{~B}$ resulted in reduced photosynthetic rate, leaf area, and fresh mass compared with W. Adding blue fraction in the light regime enhanced the photosynthetic performance by influencing the amount of chlorophyll (Chl), Chl $a / b$, and specific leaf area. Under red/blue treatments, the electron transport rate and effective quantum yield of both PSII and PSI increased, while the nitrate content was reduced and flavonoids and total antioxidant capacity were unaffected.
\end{abstract}

Keywords: common ice plant; controlled environment; gas exchange; light quality.

\section{Introduction}

Light is one of the most important environmental factors for plants; it is not only the source of energy for photosynthetic activity but also acts as a key environmental signal that regulates morphological and physiological responses (Kami et al. 2010). Light quality, light quantity, light duration, and even direction are the key components of light conditions that affect plant growth, photomorphogenesis, and phytochemical metabolism (Fankhauser and Chory 1997, Zoratti et al. 2014, Bantis et al. 2018).

Nowadays, artificial lighting is widely accepted for horticultural crops produced under controlled environments such as plant factories and space agriculture (Graamans

\section{Highlights}

- Monochromatic blue reduced photosynthetic rate, leaf area, and fresh mass of ice plants

- $\Phi_{\mathrm{PSI}}, \Phi_{\mathrm{PSI}}$, and $P_{\mathrm{N}}$ increased with the proportion of blue in the dichromatic treatments

- Narrow-band treatments reduced the nitrate content accumulation in the leaves of ice plants
Received 16 June 2021

Accepted 21 September 2021

Published online 26 October 2021

${ }^{+}$Corresponding author

e-mail: zhengliang@cau.edu.cn

phone: 0086-10-62737400

Abbreviations: $\mathrm{AQE}$ - apparent quantum efficiency; Car - carotenoids; Chl - chlorophyll; $C_{\mathrm{i}}$ - intercellular $\mathrm{CO}_{2}$ concentration; $\mathrm{DM}$ - dry mass; FM - fresh mass; $\mathrm{F}_{\mathrm{v}} / \mathrm{F}_{\mathrm{m}}-$ maximal quantum yield of PSII photochemistry in the dark-adapted state; $g_{\mathrm{s}}-$ stomatal conductance; LA - leaf area; LCP - light-compensation point; MDA - malondialdehyde content; $P_{\mathrm{N}}$ - net photosynthetic rate; $P_{\mathrm{Nmax}}-$ light-saturated net photosynthetic rate; $R_{\mathrm{D}}$ - dark respiration rate; $\Phi_{\mathrm{NA}}$ - quantum yield of nonphotochemical energy dissipation in PSI in the light-adapted state due to the acceptor-side limitation; $\Phi_{\mathrm{ND}}$ - quantum yield of nonphotochemical energy dissipation in PSI in the light-adapted state due to the donor-side limitation; $\Phi_{\mathrm{NO}}-$ quantum yield of nonregulated fluorescence quenching; $\Phi_{\mathrm{NPQ}}-$ quantum yield of nonphotochemical quenching; $\Phi_{\mathrm{PSI}}-$ effective quantum yield of PSI photochemistry in the light-adapted state; $\Phi_{\mathrm{PSII}}-$ effective quantum yield of PSII photochemistry in the light-adapted state.

Conflict of interest: The authors declare that they have no conflict of interest. 
et al. 2018). The recent development of LEDs (lightemitting diodes), which allows targeted manipulation of the spectrum composition and intensity for artificial lighting, has provided an opportunity to maximize crop productivity and accumulation of health beneficial compounds for both commercial and research perspectives in greenhouse crop cultivation (Kozai 2016, Pattison et al. 2018, Kusuma et al. 2020, Paradiso and Proietti 2021). Red light photons generally provide the highest spectrumdependent quantum yield (McCree 1971, Zheng et al. 2019), whereas additional blue light is necessary because of its positive influences on chlorophyll $(\mathrm{Chl})$ biosynthesis and stomatal movement (Im et al. 2006, Ilić and Fallik 2017). The previous investigation reported that adding blue light to the light spectrum increased the photosynthetic rate of rice leaves, which promoted the accumulation of nitrogen content in the leaves and dry matter production (Matsuda et al. 2004); this was also confirmed in other plant species, such as cucumber (Hogewoning et al. 2010), lettuce (Wang et al. 2016), and chrysanthemum (Jeong et al. 2014). Although the necessity of blue light is commonly accepted, the optimal red/blue ratio could be species-dependent (Piovene et al. 2015).

Mesembryanthemum crystallinum (the common ice plant) is an annual succulent plant native to the southwest African desert; it employs $\mathrm{C}_{3}$ photosynthesis under well-watered conditions but optionally shifts to CAM (crassulacean acid metabolism) pathway when exposed to stress conditions such as drought, salinity, and high temperature (Lee et al. 2019). M. crystallinum is rich in minerals, antioxidants, and polyols, therefore it has important functions in disease prevention and health promotion (Loconsole et al. 2019, Sánchez-Faure et al. 2020). Nowadays, M. crystallinum has been entered into cosmetics because of its good moisturizing effect and medicinal value, whereas it is also being used as an emerging healthy fresh leafy vegetable in many countries (Rahman et al. 2011, Kim et al. 2021).

Light quality manipulation might be a safe and more reliable way to improve the yield formation and nutritional composition for commercial ice plant cultivation. Aimed to provide a theoretical basis on light environment control for the production of ice plants under artificial lighting conditions, this study was performed to investigate the growth, photomorphogenesis, photosynthetic efficiency, and antioxidant capacity of $M$. crystallinum grown under different combinations of blue and red light, as well as white light.

\section{Materials and methods}

Plant material and treatments: The experiments were conducted in a climate-controlled growth chamber at China Agriculture University (Haidian Beijing, China). Seeds of Mesembryanthemum crystallinum were pregerminated and sown in plug trays, and then allowed to grow under white light for four weeks to obtain the young seedlings. Uniform seedlings were selected and transplanted into individual plastic pots $(300 \mathrm{~mL})$ with a peat-based substrate, and then subjected to different light treatments. The light intensity at canopy level was set at $150 \mu \mathrm{mol}$ (photon) $\mathrm{m}^{-2} \mathrm{~s}^{-1}$ by adjusting the forward current of LED lamps and a photoperiod of $14 \mathrm{~h}$ per day was given. The day and night temperatures in the growth chamber were maintained at 25 and $18^{\circ} \mathrm{C}$, relative humidity was set at $70-75 \%$. Plants received irrigation with $1 / 2$ dose Hoagland's nutrient solution every $2 \mathrm{~d}$ for the first $10 \mathrm{~d}$, once a day for the later days.

Five light quality groups were set for the experiment as follows: white light control (W); a combination of red (R) and blue (B) light (15, 40, and 70\%B, respectively); monochromatic blue light $(100 \% \mathrm{~B})$. The light was supplied with LEDs (R: peak at $660 \mathrm{~nm}$; B: peak at $460 \mathrm{~nm}$ ), the light spectra (Fig. 1) were recorded with a spectrometer (AvaSpec-ULS2048, Avantes Inc., Apeldoorn, NL). The seedlings were cultivated under different light qualities until the adult stage for $30 \mathrm{~d}$, then the gas exchange and Chl fluorescence measurement were conducted on the second fully expanded leaf. After that, the same leaf was immediately frozen with liquid nitrogen and stored at $-80^{\circ} \mathrm{C}$ until further biochemical assay.

Total leaf area, dry mass, and fresh mass: The fully expanded leaves of each plant were excised and scanned with a flatbed image scanner (Epson Perfection V19, Epson, Japan), the total leaf area was determined with Image $J$ (NIH, Bethesda, MD, USA), specific leaf area (SLA) was calculated as the ratio of leaf area to leaf dry mass. Plants were harvested and weighted with an analytical balance to determine their fresh mass (FM), then sequentially ovendried at $105^{\circ} \mathrm{C}$ for $3 \mathrm{~h}$ and $85^{\circ} \mathrm{C}$ for $3 \mathrm{~d}$ until the constant mass was reached to obtain the dry mass (DM).

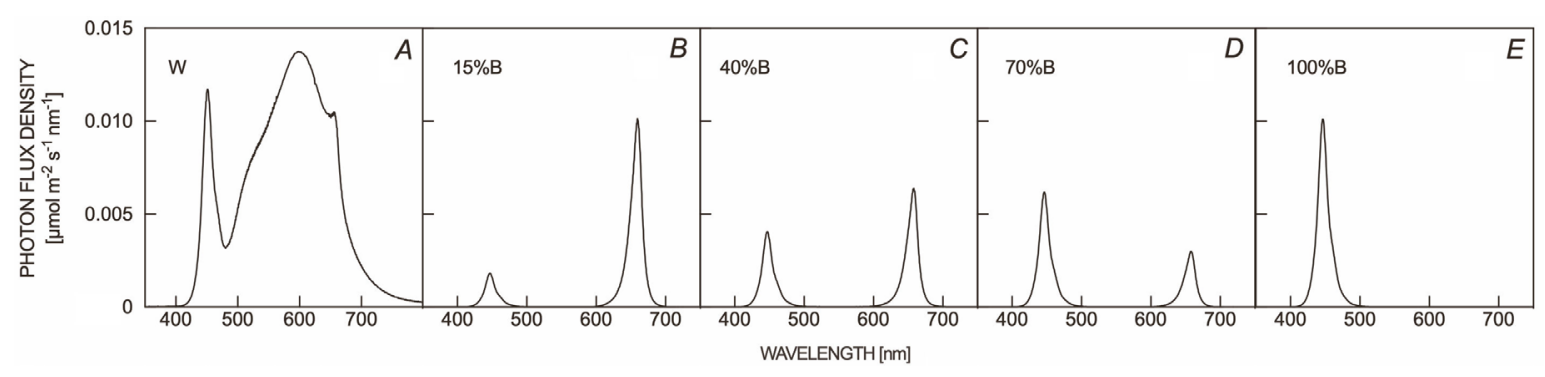

Fig. 1. Light spectrum of the different light quality treatments (W, $15 \% \mathrm{~B}, 40 \% \mathrm{~B}, 70 \% \mathrm{~B}, 100 \% \mathrm{~B})$. Spectral scan was performed each $0.6 \mathrm{~nm}$ with an optical fiber spectrometer (AvaSpec-ULS2048, Avantes Inc., Apeldoorn, NL). 
Leaf pigment contents: The homogenized leaf sample was extracted with $10 \mathrm{~mL}$ of $80 \%$ aqueous acetone at $4^{\circ} \mathrm{C}$ for $24 \mathrm{~h}$ under dark conditions. The absorbance at $470,645,663 \mathrm{~nm}$ of the supernatant was measured using a UV-VIS spectrophotometer (UV-2802, Unico Inc., Shanghai, China). The $\mathrm{Chl} a, \mathrm{Chl} b$, and carotenoid (Car) contents were calculated using the following formulas referring to Wellburn and Lichtenthaler (1984): Chl $a=$ $12.25 \mathrm{~A}_{663}-2.79 \mathrm{~A}_{645}$, Chl $b=21.5 \mathrm{~A}_{645}-5.1 \mathrm{~A}_{663}$, Car $=$ $\left(1,000 \mathrm{~A}_{470}-1.82 \mathrm{Chl} a-85.02 \mathrm{Chl} b\right) / 198$.

Phytochemicals content: The malondialdehyde (MDA) content was determined following the method described by Hodges et al. (1999). The homogenized leaf sample was extracted with $10 \mathrm{~mL}$ of $80 \%$ ethanol and centrifuged at $10,000 \mathrm{rpm}$. The supernatant $(0.5 \mathrm{~mL})$ was added to either solution without TBA $(20 \%$ trichloroacetic acid, $0.01 \%$ butylated hydroxytoluene) or solution with TBA (20\% trichloroacetic acid, $0.01 \%$ butylated hydroxytoluene, $0.65 \% \mathrm{TBA}$ ), respectively. The mixture was vigorously shaken and incubated at $95^{\circ} \mathrm{C}$ for $25 \mathrm{~min}$ and immediately cooled down on an ice bath. The absorbance of both extracts was measured at 440, 532, and $600 \mathrm{~nm}$. The MDA content was calculated as: $\mathrm{A}=$ $\left(\mathrm{A}_{532+\mathrm{TBA}}-\mathrm{A}_{600+\mathrm{TBA}}\right)-\left(\mathrm{A}_{532-\mathrm{TBA}}-\mathrm{A}_{600-\mathrm{TBA}}\right), \mathrm{B}=\left(\mathrm{A}_{440+\mathrm{TBA}}-\right.$ $\left.\mathrm{A}_{600+\mathrm{TBA}}\right) \times 0.0571$, MDA equivalents $\left[\mathrm{nmol} \mathrm{ml^{-1 }}\right.$ ] $(\mathrm{A}-\mathrm{B} / 157,000) \times 10^{6}$.

The nitrate content was determined following $\mathrm{Li}$ et al. (2016). The mixture composed of $0.4 \mathrm{~mL}$ of $5 \%$ salicylic acid-sulfuric acid solution, $9.5 \mathrm{~mL}$ of $8 \%$ $\mathrm{NaOH}$, and $0.1 \mathrm{~mL}$ of leaf extract was boiled in a water bath for $30 \mathrm{~min}$. The liquid supernatant was measured spectrophotometrically (UV-2802, Unico Inc., Shanghai, China) at $410 \mathrm{~nm}$ to determine the nitrate content. The nitrate content was calculated as $(\mathrm{C} \times \mathrm{V}) / \mathrm{W}$, where $\mathrm{C}$ is the nitrate concentration calculated using a standard curve $(\mathrm{C}=0.0074 \mathrm{~A}+0.0049)\left[\mu \mathrm{g} \mathrm{mL}^{-1}\right], \mathrm{A}$ is the absorbance at $410 \mathrm{~nm}, \mathrm{~V}$ is the volume for sample extraction $[\mathrm{mL}], \mathrm{W}$ is the sample mass [g].

The total protein content was determined with the Coomassie Brilliant Blue dye method (Bradford 1976). Homogenized leaves were extracted with $3 \mathrm{~mL}$ of distilled water and centrifuged at $10,000 \mathrm{rpm}$ for $10 \mathrm{~min}$ at $4{ }^{\circ} \mathrm{C}$, then $1 \mathrm{~mL}$ of the supernatant was mixed well with $5 \mathrm{~mL}$ of Coomassie Brilliant Blue $G-250\left(0.1 \mathrm{~g} \mathrm{~L}^{-1}\right)$. The absorbance at $595 \mathrm{~nm}$ was measured using a spectrophotometer (UV-2802, Unico Inc., Shanghai, China); the total soluble protein was calculated as $\mathrm{mg} \mathrm{g}^{-1}(\mathrm{FM})$ using the calibration curve $(C=0.0041 \mathrm{~A}+0.095)$.

Total phenolic content was determined with the FolinCiocalteu phenol reagent (Kaulmann et al. 2014). Briefly, leaf material $(250 \mathrm{mg})$ was extracted with $10 \mathrm{~mL}$ of $80 \%$ methanol. The extract $(200 \mu \mathrm{L})$ was added to $1.5 \mathrm{~mL}$ of Folin-Ciocalteu (1:10) reagent. After $4 \mathrm{~min}, 800 \mu \mathrm{L}$ of $7.5 \% \mathrm{Na}_{2} \mathrm{CO}_{3}$ was added and mixed well, the mixture was incubated at room temperature in the dark for $2 \mathrm{~h}$. The absorbance of the mixture at $765 \mathrm{~nm}$ was recorded. Total phenolic content calculated with an external calibration curve of gallic acid and expressed as $\mathrm{mg}$ (gallic acid equivalent) $\mathrm{g}^{-1}$ (FM).
Total flavonoid content was evaluated using the aluminum chloride method (Kaulmann et al. 2014) with minor modifications. The extract $(400 \mu \mathrm{L})$ was mixed well with $600 \mu \mathrm{L}$ of distilled water and $60 \mu \mathrm{L}$ of $5 \% \mathrm{NaNO}_{2}$ in a $15-\mathrm{mL}$ tube. After $5 \mathrm{~min}, 60 \mu \mathrm{L}$ of $10 \% \mathrm{AlCl}_{3}$ was added. After $6 \mathrm{~min}, 0.4 \mathrm{~mL}$ of $1.0 \mathrm{M} \mathrm{NaOH}$ and $0.4 \mathrm{~mL}$ of distilled water were added and mixed thoroughly. The absorbance at $510 \mathrm{~nm}$ was read after $15 \mathrm{~min}$. The total flavonoid content was calculated with a rutin external calibration curve and expressed as $\mathrm{mg}$ (rutin equivalent) $\mathrm{g}^{-1}$ (FM).

Total antioxidant activity was determined with the same extract for total flavonoids assay following the method described by Re et al. (1999). The reaction mixture was composed with $0.1 \mathrm{~mL}$ of the extract and $0.9 \mathrm{~mL}$

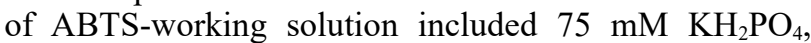
$20 \mathrm{mM}$ 2,2'-azinobis(3-ethylbenzothiazoline-6-sulfonic acid) diammonium salt (ABTS), horseradish peroxidase (HRP) stock (aqueous solution, which contains HRP and ammonium sulphate with concentration at 0.08 and $13 \mathrm{mg} \mathrm{ml}^{-1}$, respectively), and $\mathrm{H}_{2} \mathrm{O}_{2}$ stock (35\% aqueous solution). The absorbance at $734 \mathrm{~nm}$ was measured using a UV-VIS spectrophotometer (UV-2802, Unico Inc., Shanghai, China) after incubating for $6 \mathrm{~min}$, and the total antioxidant capacity was expressed as $\mu \mathrm{mol}(\mathrm{L}-\mathrm{AA}$ equivalent) $\mathrm{g}^{-1}(\mathrm{FM})$. The total antioxidant activity was calculated as $(\mathrm{C} \times \mathrm{V}) / \mathrm{W}$, where $\mathrm{C}$ is the concentration of L-AA calculated using a standard curve $(\mathrm{C}=-20.69 \mathrm{~A}+$ 0.4649 ) $\left[\mu \mathrm{mol} \mathrm{L} \mathrm{L}^{-1}\right], \mathrm{A}$ is the absorbance at $734 \mathrm{~nm}, \mathrm{~V}$ is the volume of the supernatant used for absorbance determination $[\mu \mathrm{L}]$, and $\mathrm{W}$ is the mass of sample $[\mathrm{g}]$.

Gas-exchange parameters: Net photosynthetic rate $\left(P_{\mathrm{N}}\right)$, stomatal conductance $\left(g_{\mathrm{s}}\right)$, and intercellular $\mathrm{CO}_{2}$ concentration $\left(C_{\mathrm{i}}\right)$ were determined using an $L I-6400 X T$ gas-exchange analyzer ( $\mathrm{Li}$-Cor Inc., Lincoln, NE, USA). Apparent mesophyll conductance (the conductance of $\mathrm{CO}_{2}$ from the stomatal cavity to the chloroplast) was calculated as the ratio of $P_{\mathrm{N}}$ to $C_{\mathrm{i}}$ (Fischer et al. 1998). The measuring area of the standard leaf chamber was $4 \mathrm{~cm}^{2}$, the $\mathrm{CO}_{2}$ concentration was adjusted to $400 \mu \mathrm{mol}$ $\mathrm{mol}^{-1}$ supplied by a $\mathrm{CO}_{2}$ container, and the flow rate of $500 \mu \mathrm{mol} \mathrm{s}^{-1}$. Leaf temperature and PPFD were maintained under the same conditions as that of the plant growth conditions at $25^{\circ} \mathrm{C}$ and $150 \mu \mathrm{mol} \mathrm{m} \mathrm{m}^{-1} \mathrm{~s}^{-1}$, respectively. The gas-exchange parameters were obtained by averaging the records of a 30-s period upon a stable photosynthetic rate was reached (approximately $5 \mathrm{~min}$ ). $P_{\mathrm{N}}-$ PPFD curve was fitted using a modified rectangular hyperbola model with the $P_{\mathrm{N}}$ data and light intensity to calculate the light-saturated maximum photosynthetic rate $\left(P_{\mathrm{Nmax}}\right)$, apparent quantum efficiency (AQE), light-compensation point (LCP), and dark respiration rate $\left(R_{\mathrm{D}}\right)$ according to Ye et al. (2013). The interval of light intensities of the $P_{\mathrm{N}}-$ PPFD curve was ranging from 2,000 to $0 \mu \mathrm{mol} \mathrm{m} \mathrm{m}^{-2} \mathrm{~s}^{-1}$, the minimum waiting time was set to $120 \mathrm{~s}$, and the maximum waiting time was set to $200 \mathrm{~s}$.

Chl fluorescence and $\mathbf{P}_{700}$ measurement of the fully developed leaf were determined simultaneously using a 
PAM fluorometer (Dual-PAM-100, Walz GmbH, Effeltrich, Germany). Plants were pre-darkened for $30 \mathrm{~min}$ before determination. $\mathrm{F}_{\mathrm{m}}$ and $\mathrm{P}_{\mathrm{m}}$ were obtained by applying two saturation pulses. The leaf was then subjected to a light adaption phase with actinic light intensity at $150 \mu \mathrm{mol}$ (photon) $\mathrm{m}^{-2} \mathrm{~s}^{-1}$, saturating light pulses were given every $60 \mathrm{~s}$, and a far-red pulse after the actinic light was turned off. $F_{s}$ represents steady-state chlorophyll fluorescence for the light-adapted state, while $\mathrm{F}_{\mathrm{m}}{ }^{\prime}$ is the maximum fluorescence in the light-adapted state. The PSII parameters were determined as described by Lazár (2015). The maximum photochemical efficiency of PSII for the dark-adapted state was calculated as $\mathrm{F}_{\mathrm{v}} / \mathrm{F}_{\mathrm{m}}=\left(\mathrm{F}_{\mathrm{m}}-\mathrm{F}_{0}\right) / \mathrm{F}_{\mathrm{m}}$, the effective quantum yield of PSII photochemistry for the light-adapted state as $\Phi_{\mathrm{PSII}}=\left(\mathrm{F}_{\mathrm{m}}{ }^{\prime}-\mathrm{F}_{\mathrm{s}}\right) / \mathrm{F}_{\mathrm{m}}{ }^{\prime}$, the quantum yield of nonphotochemical fluorescence quenching was calculated as $\Phi_{\mathrm{NPQ}}=\mathrm{F}_{\mathrm{s}} / \mathrm{F}_{\mathrm{m}}{ }^{\prime}-\mathrm{F}_{\mathrm{s}} / \mathrm{F}_{\mathrm{m}}$, and the quantum yield of nonregulated fluorescence quenching in PSII was calculated as $\Phi_{\mathrm{NO}}=\mathrm{F}_{\mathrm{s}} / \mathrm{F}_{\mathrm{m}}$, where $\Phi_{\mathrm{PSII}}+\Phi_{\mathrm{NPQ}}+\Phi_{\mathrm{NO}}=1$.

The PSI parameters were measured according to Klughammer and Schreiber (1994) as follows: $\Phi_{\mathrm{PSI}}=$ $\left(\mathrm{P}_{\mathrm{m}}{ }^{\prime}-\mathrm{P}\right) / \mathrm{P}_{\mathrm{m}}, \Phi_{\mathrm{ND}}=\mathrm{P} / \mathrm{P}_{\mathrm{m}}$, and $\Phi_{\mathrm{NA}}=\left(\mathrm{P}_{\mathrm{m}}-\mathrm{P}_{\mathrm{m}}{ }^{\prime}\right) / \mathrm{P}_{\mathrm{m}} . \mathrm{P}$ is the relative electron transfer efficiency, while $\mathrm{P}_{\mathrm{m}}{ }^{\prime}$ is the maximum relative electron transfer efficiency. $\Phi_{\mathrm{PSI}}, \Phi_{\mathrm{ND}}$, and $\Phi_{\mathrm{NA}}$ represent the effective quantum yield of PSI photochemistry in the light-adapted state, quantum yield of nonphotochemical energy dissipation in PSI in the light-adapted state due to the donor-side limitation, and quantum yield of nonphotochemical energy dissipation in PSI in the light-adapted state due to the acceptor-side limitation, respectively.
Statistical analysis: Five random individual plants were considered as five biological replicates, except quadruplicates for biomass and $\mathrm{Chl}$ fluorescence measurement were conducted. Statistical analysis was performed with SPSS 26.0 (SPSS Inc., Chicago, IL, USA). After verifying homoscedasticity by Levene's test, a one-way analysis of variance ( $A N O V A)$ was conducted to test for significance between different treatments and Turkey's multiple range test at $p<0.05$ for ad hoc analysis. Correlations between traits were tested using Pearson's correlation coefficient.

\section{Results}

Plant growth and morphology: The greatest DM was observed under $40 \% \mathrm{~B}$, although no significant difference was detected compared to other treatments (Table 1). The greatest FM was recorded for $40 \% \mathrm{~B}$ and $\mathrm{W}$, while it was reduced under $15 \% \mathrm{~B}$ and $70 \% \mathrm{~B}$, and significantly decreased under $70 \% \mathrm{~B}$.

The total leaf area was the greatest under W; compared with $\mathrm{W}$, no statistical difference was found for $15 \% \mathrm{~B}$ and $40 \% \mathrm{~B}$ treatments but it was reduced under $70 \% \mathrm{~B}$ and significantly decreased under $100 \% \mathrm{~B}$. The plants grown under white light resulted in the greatest SLA, which was not statistically different from that under $15 \%$ B. SLA under $40 \% \mathrm{~B}$ and $15 \% \mathrm{~B}$ was lower than that of $\mathrm{W}$ though there was no significant difference between them, whereas the plants under $100 \% \mathrm{~B}$ resulted in the lowest specific leaf area.

Pigment content: Leaf Chl and carotenoids (Car) contents were influenced by light quality (Table 2). Overall, the

Table 1. Plant growth and leaf morphology of Mesembryanthemum crystallinum grown under different combinations of red and blue LED light. Values are means \pm SE. Different letters indicate significant difference, as determined by Tukey's multiple comparison tests $(P<0.05, n=4)$.

\begin{tabular}{lllll}
\hline & $\begin{array}{l}\text { Fresh mass } \\
\text { [g per plant] }\end{array}$ & $\begin{array}{l}\text { Dry mass } \\
\text { [g per plant] }\end{array}$ & $\begin{array}{l}\text { Leaf area } \\
{\left[\mathrm{cm}^{2} \text { per plant] }\right.}\end{array}$ & $\begin{array}{l}\text { Specific leaf area } \\
{\left[\mathrm{cm}^{2} \mathrm{~g}^{-1}\right]}\end{array}$ \\
\hline $\mathrm{W}$ & $43.38 \pm 5.81^{\mathrm{a}}$ & $0.44 \pm 0.07^{\mathrm{a}}$ & $349.44 \pm 34.74^{\mathrm{a}}$ & $790.0 \pm 99.0^{\mathrm{a}}$ \\
$15 \% \mathrm{~B}$ & $32.15 \pm 3.02^{\mathrm{ab}}$ & $0.39 \pm 0.03^{\mathrm{a}}$ & $288.01 \pm 26.90^{\mathrm{a}}$ & $736.6 \pm 47.9^{\mathrm{a}}$ \\
$40 \% \mathrm{~B}$ & $41.97 \pm 3.40^{\mathrm{a}}$ & $0.54 \pm 0.03^{\mathrm{a}}$ & $336.25 \pm 19.00^{\mathrm{a}}$ & $633.2 \pm 53.3^{\mathrm{ab}}$ \\
$70 \% \mathrm{~B}$ & $28.70 \pm 2.48^{\mathrm{ab}}$ & $0.45 \pm 0.03^{\mathrm{a}}$ & $253.85 \pm 18.59^{\mathrm{ab}}$ & $568.6 \pm 6.7^{\mathrm{ab}}$ \\
$100 \% \mathrm{~B}$ & $20.47 \pm 0.48^{\mathrm{b}}$ & $0.39 \pm 0.02^{\mathrm{a}}$ & $174.45 \pm 5.53^{\mathrm{b}}$ & $449.9 \pm 32.9^{\mathrm{b}}$ \\
\hline
\end{tabular}

Table 2. Chlorophyll and carotenoid contents of Mesembryanthemum crystallinum grown under different combinations of red and blue LED light. Values are means \pm SE. Different letters indicate significant difference, as determined by Tukey's multiple comparison tests $(P<0.05, n=4)$.

\begin{tabular}{lllll}
\hline & $\begin{array}{l}\text { Chl content } \\
{\left[\mathrm{mg} \mathrm{g}^{-1}(\mathrm{FM})\right]}\end{array}$ & $\begin{array}{l}\text { Car content } \\
{\left[\mathrm{mg} \mathrm{g}^{-1}(\mathrm{FM})\right]}\end{array}$ & Chl a/b & Chl/Car \\
\hline $\mathrm{W}$ & $0.219 \pm 0.009^{\mathrm{bc}}$ & $0.047 \pm 0.002^{\mathrm{bc}}$ & $3.41 \pm 0.05^{\mathrm{b}}$ & $4.65 \pm 0.06^{\mathrm{a}}$ \\
$15 \% \mathrm{~B}$ & $0.228 \pm 0.015^{\mathrm{bc}}$ & $0.046 \pm 0.002^{\mathrm{bc}}$ & $3.58 \pm 0.04^{\mathrm{ab}}$ & $4.99 \pm 0.13^{\mathrm{a}}$ \\
$40 \% \mathrm{~B}$ & $0.246 \pm 0.013^{\mathrm{b}}$ & $0.050 \pm 0.002^{\mathrm{ab}}$ & $3.69 \pm 0.06^{\mathrm{a}}$ & $4.94 \pm 0.22^{\mathrm{a}}$ \\
$70 \% \mathrm{~B}$ & $0.284 \pm 0.011^{\mathrm{a}}$ & $0.057 \pm 0.003^{\mathrm{a}}$ & $3.70 \pm 0.05^{\mathrm{a}}$ & $4.98 \pm 0.07^{\mathrm{a}}$ \\
$100 \% \mathrm{~B}$ & $0.191 \pm 0.006^{\mathrm{c}}$ & $0.040 \pm 0.002^{\mathrm{c}}$ & $3.79 \pm 0.08^{\mathrm{a}}$ & $4.75 \pm 0.08^{\mathrm{a}}$ \\
\hline
\end{tabular}


total $\mathrm{Chl}$ and Car content increased with increasing blue light proportion for the dichromatic light treatments, and plants under $70 \% \mathrm{~B}$ resulted in the greatest total $\mathrm{Chl}$ and Car content. Monochromatic B led to the lowest Chl and Car content, which was significantly reduced compared with the $\mathrm{W}$ control. For the $\mathrm{Chl} a / b$ ratio, narrow-band light treatments induced a greater ratio of $\mathrm{Chl} a / b$ in comparison with W. There were no significant differences in the $\mathrm{Chl} / \mathrm{Car}$ ratio between all the treatments.

Gas-exchange parameters: Evaluation of leaf gas exchange showed that red/blue light influenced the photosynthesis-related parameters (Fig. 2). $P_{\mathrm{N}}$ was the lowest under $\mathrm{W}$ and increased after the treatment of $40 \% \mathrm{~B}$, while it was significantly greater under $70 \% \mathrm{~B}$. $C_{\mathrm{i}}$ was higher for the dichromatic light treatments than that of control, $100 \% \mathrm{~B}$ showed no difference from $\mathrm{W}$. The greatest value of stomatal conductance $\left(g_{\mathrm{s}}\right)$ was recorded under $40 \% \mathrm{~B}$ treatment, while it was not different from the $\mathrm{W}, 15 \% \mathrm{~B}$, and $100 \% \mathrm{~B}$, and was significantly lower for $70 \% \mathrm{~B}$ treatment.

Compared with $\mathrm{W}$, the dark respiration rate $\left(R_{\mathrm{D}}\right)$ and LCP increased for all the dichromatic and monochromatic groups (Fig. 3). There was no significant difference found for $P_{\mathrm{N} \max }$ for all the treatments (Fig. 3), AQE was the highest under $40 \% \mathrm{~B}$ and lower under $\mathrm{W}, 15 \% \mathrm{~B}$, and $70 \% \mathrm{~B}$ without a statistical difference, and significantly lower under $100 \% \mathrm{~B}$.

Chl fluorescence and $\mathbf{P}_{700}$ : Generally, in comparison with $\mathrm{W}$-grown plants, both $\Phi_{\mathrm{PSII}}$ and $\Phi_{\mathrm{PSI}}$ were higher under the mixture of narrow-band R and B treatments (Fig. 4), and no statistical difference was observed between these treatments. There was no significant difference for $\Phi_{\mathrm{NPQ}}$ and $\Phi_{\mathrm{NA}}$ under different light qualities. $\Phi_{\mathrm{NO}}$ and $\Phi_{\mathrm{ND}}$ were the highest under $\mathrm{W}, \Phi_{\mathrm{NO}}$ decreased with the increase of
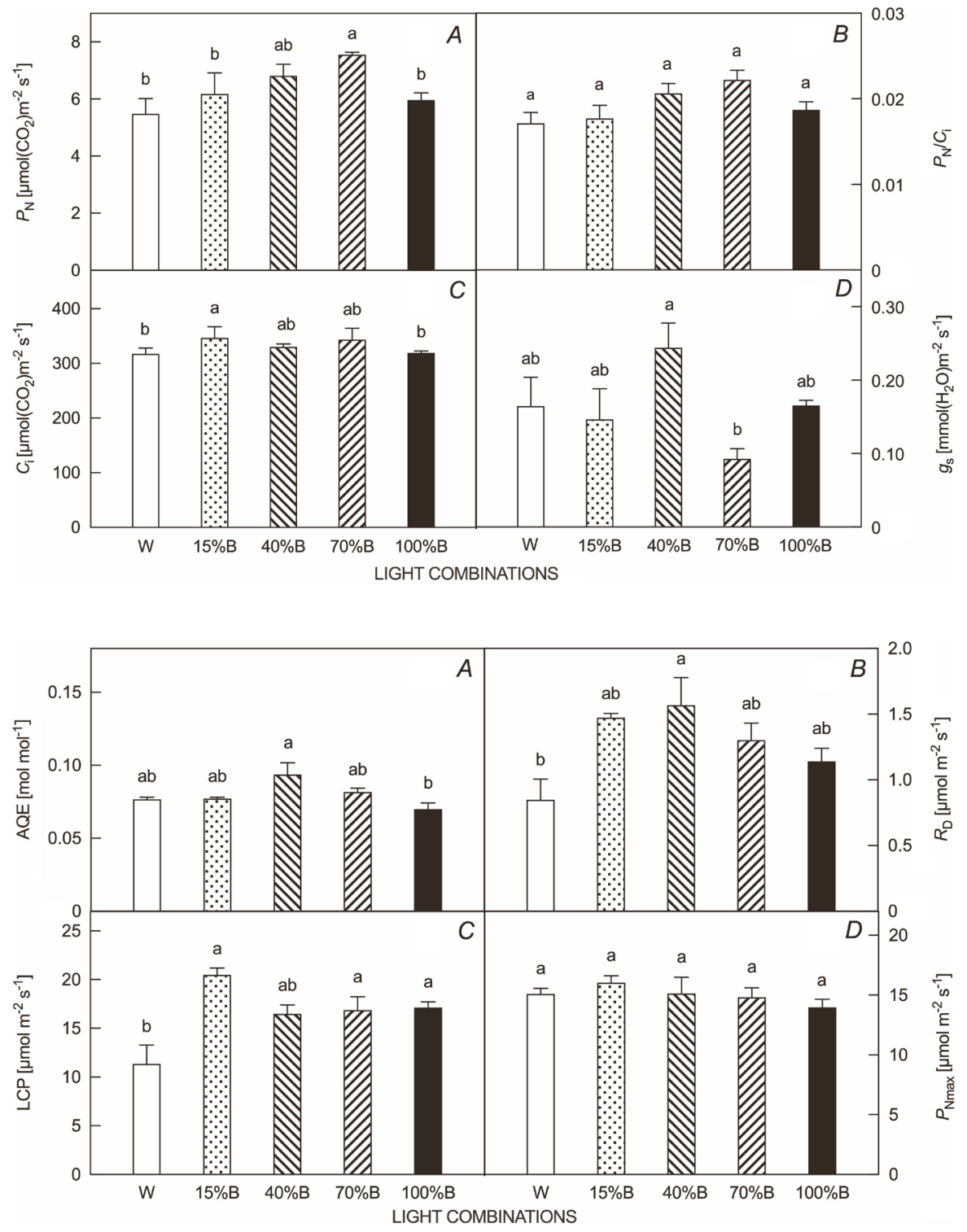

Fig. 2. Net photosynthetic rate $\left(P_{\mathrm{N}}\right)$ $(A), P_{\mathrm{N}} / C_{\mathrm{i}}$ ratio $(B)$, intercellular $\mathrm{CO}_{2}$ concentration $\left(C_{\mathrm{i}}\right)(C)$, and stomatal conductance $\left(g_{\mathrm{s}}\right)(D)$ of Mesembryanthemum crystallinum grown under different combinations of red and blue light. Values are means \pm SE. Different letters indicate statistical differences as determined by Tukey's multiple comparison tests $(P<0.05, n=5)$.

Fig. 3. Apparent quantum efficiency (AQE) $(A)$, dark respiration rate $\left(R_{\mathrm{D}}\right)(B)$, light-compensation point (LCP) (C), maximum net photosynthetic rate $\left(P_{\mathrm{Nmax}}\right)(D)$ of Mesembryanthemum crystallinum grown under different combinations of red and blue light. Values are means \pm SE. Different letters indicate statistical differences as determined by Tukey's multiple comparison tests $(P<0.05, n=5)$. 


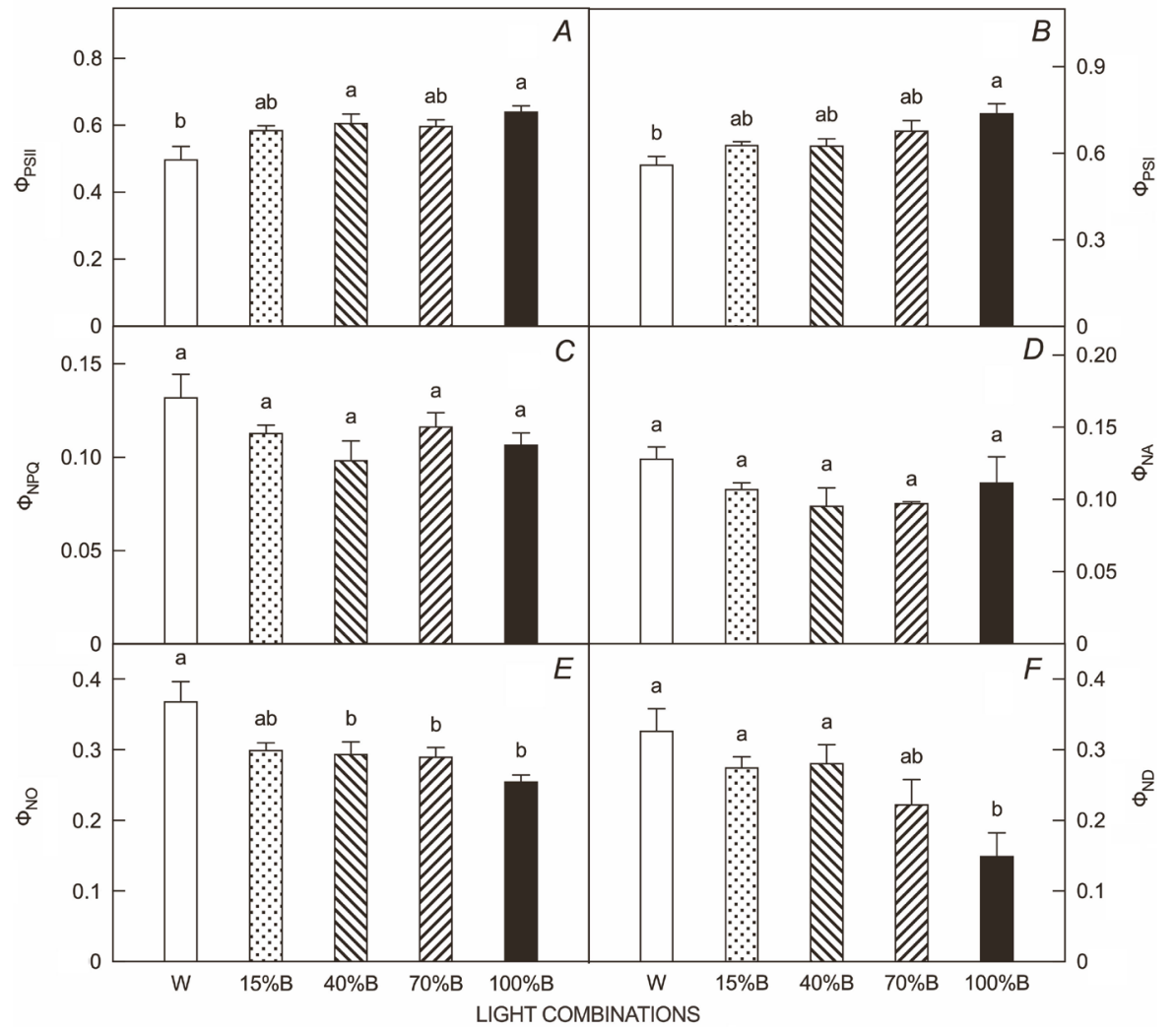

Fig. 4. The quantum yield fractions of three processes: effective quantum yield of PSII photochemistry in light-adapted state $\left(\Phi_{\mathrm{PSII}}\right)(A)$, regulated nonphotochemical heat dissipation $\left(\Phi_{\mathrm{NPQ}}\right)(C)$, and other nonphotochemical losses $\left(\Phi_{\mathrm{NO}}\right)(E)$; effective quantum yield of PSI photochemistry in light-adapted state $\left(\Phi_{\mathrm{PSI}}\right)(B)$, quantum yield of nonphotochemical energy dissipation in PSI in light-adapted state due to the acceptor-side limitation $\left(\Phi_{\mathrm{NA}}\right)$ $(D)$, and quantum yield of nonphotochemical energy dissipation in PSI in light-adapted state due to the donor-side limitation $\left(\Phi_{\mathrm{ND}}\right)(F)$ of Mesembryanthemum crystallinum grown under different combinations of red and blue light. Values are means \pm SE. Different letters indicate statistical differences as determined by Tukey's multiple comparison tests $(P<0.05, n=5)$.

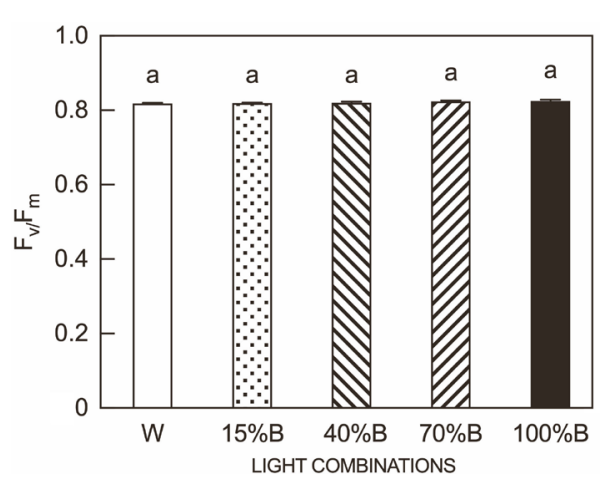

Fig. 5. Maximal quantum yield of PSII photochemistry in darkadapted state $\left(\mathrm{F}_{\mathrm{v}} / \mathrm{F}_{\mathrm{m}}\right)$ of Mesembryanthemum crystallinum grown under different combinations of red and blue light. Values are means \pm SE. Different letters indicate statistical differences as determined by Tukey's multiple comparison tests $(P<0.05, n=5)$.

blue light ratio, and was significantly lower under $40 \% \mathrm{~B}$, $70 \% \mathrm{~B}$, and $100 \% \mathrm{~B}$ while $\Phi_{\mathrm{ND}}$ decreased for the plants under $70 \% \mathrm{~B}$ and $100 \% \mathrm{~B}$.

The ice plants grown under $100 \% \mathrm{~B}$ showed the highest $F_{v} / F_{m}$ value (Fig. 5), with no statistical difference in $F_{v} / F_{m}$ values between the plants grown under white light and $\mathrm{red} / \mathrm{blue}$-combined light treatments.

MDA, soluble protein, and nitrate content: The plants grown under $\mathrm{W}$ resulted in the lowest MDA content and soluble protein content, while MDA content increased for all the plants grown under combined red and blue light (Fig. 6). M. crystallinum grown under $70 \% \mathrm{~B}$ had the greatest protein content. The $\mathrm{W}$ control resulted in the greatest nitrate content, which was approximately $1.80 \mathrm{mg} \mathrm{g}^{-1}$ and significantly greater than the other $\mathrm{red} / \mathrm{blue} \mathrm{light} \mathrm{treatments.}$

Total antioxidant capacity, total phenol and flavonoid content: Total antioxidant activity of the leaves under $\mathrm{W}$ and $\mathrm{R} / \mathrm{B}$ combined treatments showed no statistical difference (Fig. 6); the greatest value was recorded in the $40 \% \mathrm{~B}$ treatment $\left[24.20 \mu \mathrm{mol}(\mathrm{L}-\mathrm{AA}) \mathrm{g}^{-1}(\mathrm{FM})\right]$, while the lowest value was in $70 \% \mathrm{~B}$ treatment $[20.86 \mu \mathrm{mol}(\mathrm{L}-\mathrm{AA})$ $\left.\mathrm{g}^{-1}(\mathrm{FM})\right]$. There was no significant difference between the different light treatments for the total flavonoid contents. The total phenolics content was the lowest under monochromatic blue light, while it was greater under $40 \% \mathrm{~B}, 70 \% \mathrm{~B}$, and $\mathrm{W}$, and significantly greater for the $15 \% \mathrm{~B}$ treatment.

\section{Discussion}

Plant biomass accumulation under a controlled environment is largely dictated by the light energy interception during growth. In this study, the growth and morphogenesis of the ice plants were strongly influenced by the different combinations of red and blue light. Under monochromatic blue light, plant DM, FM, and total LA were the lowest in comparison with red/blue treatments and $\mathrm{W}$. This result is not surprising as amount of previous studies have proved that monochromatic blue or red light is not conducive to 


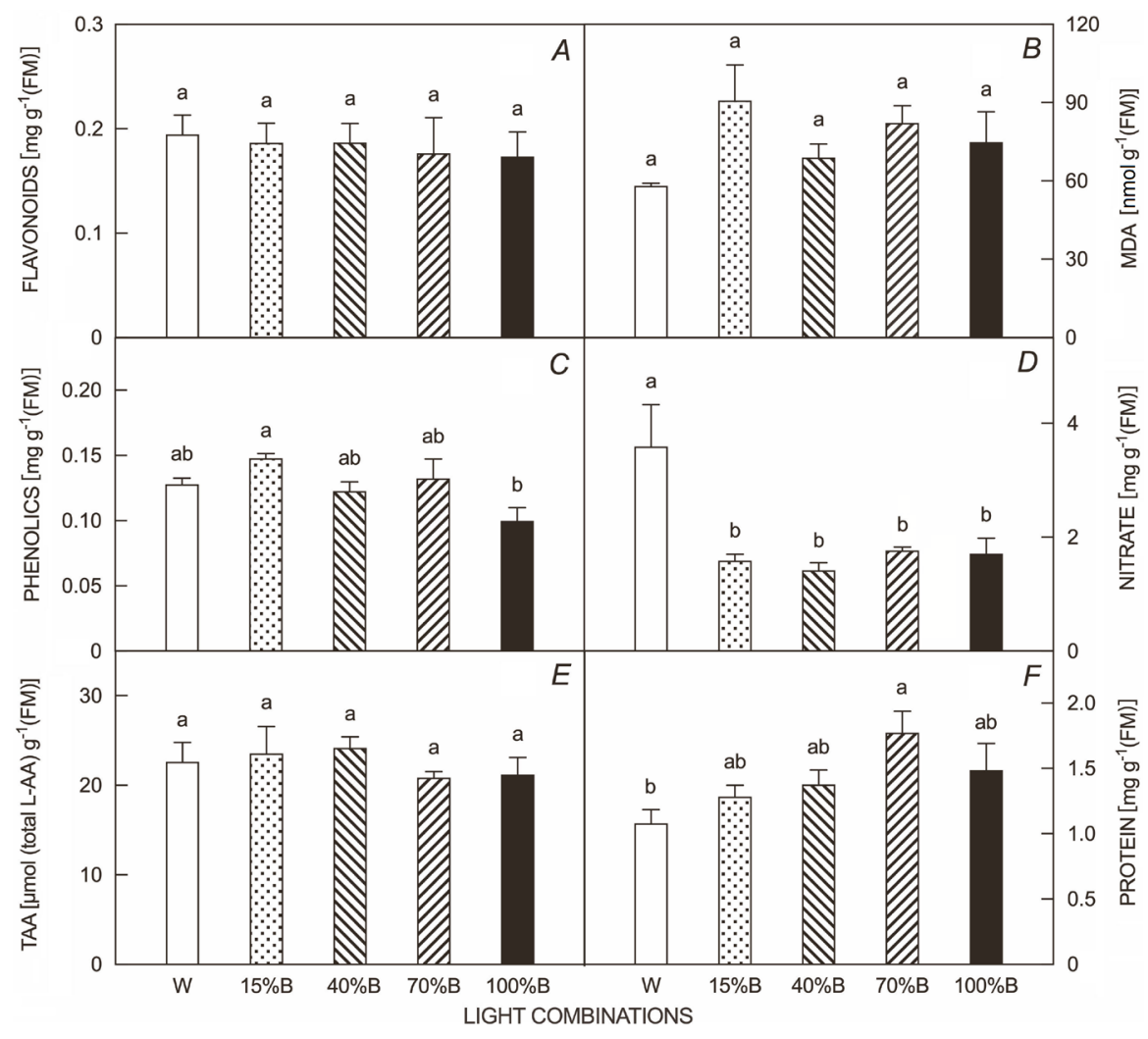

Fig. 6. Flavonoids content $(A)$, malondialdehyde (MDA) content $(B)$, phenolics content $(C)$, nitrate content $(D)$, total antioxidant activity $(E)$, and soluble protein content $(F)$ of Mesembryanthemum crystallinum grown under different combinations of red and blue LED light. Values are means \pm SE. Different letters indicate statistical differences as determined by Tukey's multiple comparison tests $(P<0.05, n=5)$ plant growth and physiological performance (Wang et al. 2009, Hogewoning et al. 2010, Chang et al. 2016, Liu et al. 2020). B (blue light) is normally associated with inhibition of cell division or expansion (Dougher and Bugbee 2004, Okello et al. 2016, Izzo et al. 2020), which in consequence lead to the reduced LA under B alone in this study (Table 1). Consistent with our findings, combing red and blue lights could promote leaf expansion and biomass accumulation in comparison with monochromatic $\mathrm{R}$ or B plants of leafy lettuce and rapeseed (Chang et al. 2016, Wang et al. 2016).

SLA showed a strong negative correlation with the blue light proportion for all the groups $(r=-0.926)$, which is in line with previous reports on other species including cucumber (Hogewoning et al. 2010), tomato (Zhang et al. 2019), and lettuce (Lin et al. 2013). In our study, the $P_{\mathrm{N}}$ of leaves increased in response to the increasing proportion of blue light ( $r=0.913$; Fig. 4), and this effect was not seen in monochromatic blue light. Lower SLA (i.e., thicker leaf) generally indicates for 'sun-type' leaves with an increased amount of photosynthesis-related pigments and enzymes, which could enhance the photosynthetic capacity per area (Evans and Poorter 2001, Vile et al. 2005), $P_{\text {Nmax }}$ showed a positive relation with SLA in our observation though it was not statistically significant $(r=0.805, P=0.100)$.

Light quality plays an important role in regulating the biosynthesis of photosynthesis-related pigments. Chl biosynthesis can be stimulated by the existence of blue photons (Sood et al. 2005), though this was also suggested to be a coaction of cryptochrome and active phytochrome (Cope et al. 2014, Hernández and Kubota 2016), absence of phytochrome in its active form might cause in case of the $100 \% \mathrm{~B}$ the decrease in Chl content in our study (Table 2). The high proportion of blue light $(59 \% \mathrm{~B}, 47 \% \mathrm{~B})$ can lead to a higher SPAD value of leaf lettuce (Son and Oh 2013), which is consistent with our results that the $\mathrm{Chl}$ and Car contents were greater for $40 \% \mathrm{~B}$ and $70 \% \mathrm{~B}$ treatments. The higher $\mathrm{Chl} a / b$ ratio normally indicates a high light-adapted photosynthetic apparatus with higher capacity for electron transport (Evans 1988); we also found an upward trend of the ratio of $\mathrm{Chl} a / b$ with the increasing percentage of blue light $(r=0.752)$. With a lower SLA and higher $\mathrm{Chl} a / b$ ratio, the ice plant leaves developed under a higher proportion of B could absorb light energy within the photosynthetic active range more efficiently (Zhen et al. 2019).

Blue light has been characterized as an environmental signal inducing stomatal and chloroplast movement mediated by its specific photoreceptors (Ichiro et al. 2016, Inoue and Kinoshita 2017). Correlation analysis between $P_{\mathrm{N}}, g_{\mathrm{s}}$, and $P_{\mathrm{N}} / C_{\mathrm{i}}$ revealed that $P_{\mathrm{N}}$ was unrelated with $g_{\mathrm{s}}(P=0.666)$ but significantly correlated with $P_{\mathrm{N}} / C_{\mathrm{i}}$ ( $r=0.959, P=0.010)$, indicating that the increase of net photosynthetic rate with the blue light fraction was due to nonstomatal limitations and mainly resulted from the changed efficiency of available $\mathrm{CO}_{2}$ to the chloroplasts in mesophyll cells (Dias and Brüggemann 2010, Arena et al. 2016). The present study shows that the net photosynthetic rate was also positively correlated with total soluble protein content ( $r=0.853, P=0.066$ ). Since Rubisco is the main protein component in plant leaves, this result suggests that the increase of total soluble protein may contribute to 
the enhancement of photosynthetic ability under a certain portion of blue light. This result is in agreement with the previous investigation that the enhanced photosynthetic rates induced by the blue light supplement to red light control were associated with higher total $\mathrm{N}$ content of leaves including Rubisco and LHCII (Matsuda et al. 2004).

$\mathrm{F}_{\mathrm{v}} / \mathrm{F}_{\mathrm{m}}$ of most unstressed plant species usually fluctuates between 0.75 and 0.85 (Quiles 2005). Our results indicated that the light treatments did not cause different degrees of stress on the ice plants. $\Phi_{\text {PSII }}$ and $\Phi_{\text {PSI }}$ reflect the fraction of absorbed light energy used for photosynthetic electron transfer. In agreement with previous reports (Hogewoning et al. 2010, Kaiser et al. 2019), both $\Phi_{\text {PSII }}$ and $\Phi_{\mathrm{PSI}}$ were the highest under blue light and the lowest under white light, indicating the greatest percentage of functional PSII centers and electron transport capacity for the plants under blue light in the present study. $\Phi_{\mathrm{NPQ}}$ and $\Phi_{\mathrm{NO}}$ reflect the quantum yield for dissipation by downregulation and other nonphotochemical losses, respectively (Dreuw et al. 2005). Plants employ NPQ mechanisms to protect themselves from excessive excitation energy by harmless heat dissipation. In the present study, there was no significant difference in $\Phi_{\mathrm{NPQ}}$ between all treatments, indicating that the ability of regulated dissipation in the form of heat was unaffected by light quality. Decreased $\Phi_{\mathrm{NO}}$ for the narrow-band R/B or B treatments indicates the increase of PSII photochemical energy conversion by reducing the fraction of nonprotective light dissipation (Shibaeva and Markovskaya 2013).

Blue light radiation, due to its relatively high photon energy, could stimulate the accumulation of reactive oxygen species, thereby causing the synthesis of protective secondary metabolites (Ort 2001, Wu et al. 2007, Jaleel et al. 2009). MDA content represents the degree of membrane lipid peroxidation and it provides an estimation of the oxidative stress level of the plants. In this study, MDA content in the red/blue light treatments was numerically greater than that in the control group, which may be attributed to the free radicals accumulation induced by these light treatments. Jing et al. (2018) have demonstrated that blue light induces the accumulation of hydrogen peroxide, which induced phenylalanine metabolism and resulted in the synthesis of phenolics and flavonoids.

Previous observation showed that compared with white light, the total phenol content of Chinese kale under red light decreased significantly, while the total phenol content under LED blue light increased (Qian et al. 2016). In this study, there was no significant difference in the total flavonoids under different blue light ratios. Adding blue light generally enhances the phenolics and flavonoids content in plants as reported in many previous reports (Ouzounis et al. 2014, Fazal et al. 2016, Zheng and Van Labeke 2017), which is mediated by regulation of the expression of key genes in their metabolic pathway (Thwe et al. 2014). This effect could be species- or genotypedependent as confirmed in our previous investigation on chrysanthemum, in which three of eight cultivars studied resulted in unaffected phenolics content in response to different light quality (Zheng and Van Labeke 2017).
Phenolic compounds and flavonoids as their subgroup in the plants are known as antioxidants with the ability in scavenging free radicals (Chen and Chen 2013). There was a positive correlation between flavonoids content and total antioxidant activity $(r=0.886, P=0.057)$ in the present study. Nitrate is necessary for plant development, though it can be reduced into nitrite-nitrogen, especially in leafy vegetables, which is a potential health hazard for humans (Bian et al. 2018). In comparison with $\mathrm{W}$, the red/blue light treatment reduced the lowest nitrate-nitrogen content in the leaves (Fig. 6), indicating the combination of the red and blue spectrum as a promising method in the production of the ice plants for preventing nitrate accumulation. This is in agreement with the conclusion of Zhou et al. (2013), who reported that pre-harvest exposure to $48 \mathrm{~h}$ continuous LED light with $20 \% \mathrm{~B}$ could effectively reduce nitrate accumulation in lettuce.

\section{References}

Arena C., Tsonev T., Doneva D. et al.: The effect of light quality on growth, photosynthesis, leaf anatomy and volatile isoprenoids of a monoterpene-emitting herbaceous species (Solanum lycopersicum L.) and an isoprene-emitting tree (Platanus orientalis L.). - Environ. Exp. Bot. 130: 122-132, 2016.

Bantis F., Smirnakou S., Ouzounis T. et al.: Current status and recent achievements in the field of horticulture with the use of light-emitting diodes (LEDs). - Sci. Hortic.-Amsterdam 235: 437-451, 2018.

Bian Z., Cheng R., Wang Y. et al.: Effect of green light on nitrate reduction and edible quality of hydroponically grown lettuce (Lactuca sativa L.) under short-term continuous light from red and blue light-emitting diodes. - Environ. Exp. Bot. 153: 63-71, 2018

Bradford M.: A rapid and sensitive method for the quantitation of microgram quantities of protein utilizing the principle of protein-dye binding. - Anal. Biochem. 72: 248-254, 1976.

Chang S., Li C., Yao X. et al.: Morphological, photosynthetic, and physiological responses of rapeseed leaf to different combinations of red and blue lights at the rosette stage. Front. Plant Sci. 7: 1144, 2016.

Chen A.Y., Chen Y.C.: A review of the dietary flavonoid, kaempferol on human health and cancer chemoprevention.Food Chem. 138: 2099-2107, 2013.

Cope K.R., Snowden M.C., Bugbee B.: Photobiological interactions of blue light and photosynthetic photon flux: Effects of monochromatic and broad-spectrum light sources. Photochem. Photobiol. 90: 574-584, 2014.

Dias M.C., Brüggemann W.: Limitations of photosynthesis in Phaseolus vulgaris under drought stress: Gas exchange, chlorophyll fluorescence and Calvin cycle enzymes. Photosynthetica 48: 96-102, 2010.

Dougher T.A.O., Bugbee B.: Long-term blue light effects on the histology of lettuce and soybean leaves and stems. - J. Am. Soc. Hortic. Sci. 129: 467-472, 2004.

Dreuw A., Fleming G.R., Head-Gordon M.: Role of electrontransfer quenching of chlorophyll fluorescence by carotenoids in non-photochemical quenching of green plants. - Biochem. Soc. T. 33: 858-862, 2005.

Evans J.R.: Acclimation by the thylakoid membranes to growth irradiance and the partitioning of nitrogen between soluble and thylakoid proteins. - Funct. Plant Biol. 15: 93-106, 1988.

Evans J.R., Poorter H.: Photosynthetic acclimation of plants to 
growth irradiance: The relative importance of specific leaf area and nitrogen partitioning in maximizing carbon gain. Plant Cell Environ. 24: 755-767, 2001.

Fankhauser C., Chory J.: Light control of plant development. Annu. Rev. Cell Dev. Biol. 13: 203-229, 1997.

Fazal H., Abbasi B.H., Ahmad N. et al.: Correlation of different spectral lights with biomass accumulation and production of antioxidant secondary metabolites in callus cultures of medicinally important Prunella vulgaris L. - J. Photoch. Photobio. B 159: 1-7, 2016.

Fischer R.A., Rees D., Sayre K.D. et al.: Wheat yield progress associated with higher stomatal conductance and photosynthetic rate, and cooler canopies. - Crop Sci. 38: 1467-1475, 1998.

Graamans L., Baeza E., van den Dobbelsteen A. et al.: Plant factories versus greenhouses: Comparison of resource use efficiency. - Agr. Syst. 160: 31-43, 2018.

Hernández R., Kubota C.: Physiological responses of cucumber seedlings under different blue and red photon flux ratios using LEDs. - Environ. Exp. Bot. 121: 66-74, 2016.

Hodges D.M., DeLong J.M., Forney C.F., Prange R.K.: Improving the thiobarbituric acid-reactive-substances assay for estimating lipid peroxidation in plant tissues containing anthocyanin and other interfering compounds. - Planta 207: 604-611, 1999.

Hogewoning S.W., Trouwborst G., Maljaars H. et al.: Blue light dose-responses of leaf photosynthesis, morphology, and chemical composition of Cucumis sativus grown under different combinations of red and blue light. - J. Exp. Bot. 61: 3107-3117, 2010.

Ichiro T., Hiroki O., Takashi F., Riichi O.: Light environment within a leaf. II. Progress in the past one-third century. J. Plant Res. 129: 353-363, 2016.

Ilić Z.S., Fallik E.: Light quality manipulation improves vegetable quality at harvest and postharvest: A review. - Environ. Exp. Bot. 139: 79-90, 2017.

Im C.S., Eberhard S., Huang K. et al:: Phototropin involvement in the expression of genes encoding chlorophyll and carotenoid biosynthesis enzymes and LHC apoproteins in Chlamydomonas reinhardtii. - Plant J. 48: 1-16, 2006.

Inoue S.I., Kinoshita T.: Blue light regulation of stomatal opening and the plasma membrane $\mathrm{H}^{+}$-ATPase. - Plant Physiol. 174: 531-538, 2017.

Izzo L.G., Mele B.H., Vitale L. et al.: The role of monochromatic red and blue light in tomato early photomorphogenesis and photosynthetic traits. - Environ. Exp. Bot. 179: 104195, 2020.

Jaleel C.A., Riadh K., Gopi R. et al.: Antioxidant defense responses: Physiological plasticity in higher plants under abiotic constraints. - Acta Physiol. Plant. 31: 427-436, 2009.

Jeong S.W., Hogewoning S.W., van Ieperen W.: Responses of supplemental blue light on flowering and stem extension growth of cut chrysanthemum. - Sci. Hortic.-Amsterdam 165: 69-74, 2014.

Jing X., Wang H., Gong B. et al:: Secondary and sucrose metabolism regulated by different light quality combinations involved in melon tolerance to powdery mildew. - Plant Physiol. Bioch. 124: 77-87, 2018.

Kaiser E., Ouzounis T., Giday H. et al.: Adding blue to red supplemental light increases biomass and yield of greenhousegrown tomatoes, but only to an optimum. - Front. Plant Sci. 9: 2002, 2019.

Kami C., Lorrain S., Hornitschek P., Fankhauser C.: Lightregulated plant growth and development. - Curr. Top. Dev. Biol. 91: 29-66, 2010.

Kaulmann A., Jonville M.C., Schneider Y.J. et al.: Carotenoids, polyphenols and micronutrient profiles of Brassica oleraceae and plum varieties and their contribution to measures of total antioxidant capacity. - Food Chem. 155: 240-250, 2014.

Kim Y.J., Kim H.M., Kim H.M. et al.: Growth and phytochemicals of ice plant (Mesembryanthemum crystallinum L.) as affected by various combined ratios of red and blue LEDs in a closed-type plant production system. - J. Appl. Res. Med. Aromat. Plants 20: 100267, 2021.

Klughammer C., Schreiber U.: An improved method, using saturating light pulses, for the determination of photosystem I quantum yield via $\mathrm{P} 700^{+}$-absorbance changes at $830 \mathrm{~nm}$. Planta 192: 261-268, 1994.

Kozai T.: Why LED lighting for Urban agriculture? - In: Kozai T., Fujiwara K., Runkle E. (ed.): LED Lighting for Urban Agriculture. Pp. 3-18. Springer, Singapore 2016.

Kusuma P., Pattison P.M., Bugbee B.: From physics to fixtures to food: current and potential LED efficacy. - Hortic. Res. 7: 56, 2020.

Lazár D.: Parameters of photosynthetic energy partitioning. J. Plant Physiol. 175: 131-147, 2015.

Lee J.W., Son K.H., Lee J.H. et al.: Growth and biochemical responses of ice plant irradiated by various visible light spectra in plant factories. - Hortic. Sci. Technol. 37: 598-608, 2019.

Li K., Li Z., Yang Q.: Improving light distribution by zoom lens for electricity savings in a plant factory with light-emitting diodes. - Front. Plant Sci. 7: 92, 2016.

Lin K.H., Huang M.Y., Huang W.D. et al.: The effects of red, blue, and white light-emitting diodes on the growth, development, and edible quality of hydroponically grown lettuce (Lactuca sativa L. var. capitata). - Sci. Hortic.-Amsterdam 150: 86-91, 2013.

Liu X., Chen Z., Jahan M.S. et al.: RNA-Seq analysis reveals the growth and photosynthetic responses of rapeseed (Brassica napus L.) under red and blue LEDs with supplemental yellow, green, or white light. - Hortic. Res. 7: 206, 2020.

Loconsole D., Murillo-Amador B., Cristiano G., De Lucia B.: Halophyte common ice plants: A future solution to arable land salinization. - Sustainability-Basel 11: 6076, 2019.

Matsuda R., Ohashi-Kaneko K., Fujiwara K. et al.: Photosynthetic characteristics of rice leaves grown under red light with or without supplemental blue light. - Plant Cell Physiol. 45: 1870-1874, 2004.

McCree K.J.: The action spectrum, absorptance and quantum yield of photosynthesis in crop plants. - Agr. Meteorol. 9: 191-216, 1971.

Okello R.C.O., de Visser P.H.B., Heuvelink E. et al.: Light mediated regulation of cell division, endoreduplication and cell expansion. - Environ. Exp. Bot. 121: 39-47, 2016.

Ort D.R.: When there is too much light. - Plant Physiol. 125: 29-32, 2001.

Ouzounis T., Fretté X., Rosenqvist E., Ottosen C.-O.: Spectral effects of supplementary lighting on the secondary metabolites in roses, chrysanthemums, and campanulas. - J. Plant Physiol. 171: 1491-1499, 2014.

Paradiso R., Proietti S.: Light-quality manipulation to control plant growth and photomorphogenesis in greenhouse horticulture: the state of the art and the opportunities of modern LED systems. - J. Plant Growth Regul., 2021. (In press)

Pattison P.M., Tsao J.Y., Brainard G.C., Bugbee B.: LEDs for photons, physiology and food. - Nature 563: 493-500, 2018.

Piovene C., Orsini F., Bosi S. et al.: Optimal red:blue ratio in LED lighting for nutraceutical indoor horticulture. - Sci. Hortic.-Amsterdam 193: 202-208, 2015.

Qian H., Liu T., Deng M. et al.: Effects of light quality on main health-promoting compounds and antioxidant capacity of Chinese kale sprouts. - Food Chem. 196: 1232-1238, 2016. 
Quiles M.J.: Photoinhibition of photosystems I and II using chlorophyll fluorescence measurements. - J. Biol. Educ. 39: 136-138, 2005.

Rahman S.M.A., Abd-Ellatif S.A., Deraz S.F., Khalil A.A.: Antibacterial activity of some wild medicinal plants collected from western Mediterranean coast, Egypt: Natural alternatives for infectious disease treatment. - Afr. J. Biotechnol. 10: 10733-10743, 2011.

Re R., Pellegrini N., Proteggente A. et al.: Antioxidant activity applying an improved ABTS radical cation decolorization assay. - Free Radical Bio. Med. 26: 1231-1237, 1999.

Sánchez-Faure A., Calvo M.M., Pérez-Jiménez J. et al.: Exploring the potential of common iceplant, seaside arrowgrass and sea fennel as edible halophytic plants. - Food Res. Int. 137: 109613, 2020

Shibaeva T.G., Markovskaya E.F.: Growth and development of cucumber Cucumis sativus L. in the prereproductive period under long photoperiods. - Russ. J. Dev. Biol. 44: 78-85, 2013.

Son K.H., Oh M.M.: Leaf shape, growth, and antioxidant phenolic compounds of two lettuce cultivars grown under various combinations of blue and red light-emitting diodes. HortScience 48: 988-995, 2013.

Sood S., Gupta V., Tripathy B.C.: Photoregulation of the greening process of wheat seedlings grown in red light. - Plant Mol. Biol. 59: 269-287, 2005.

Thwe A.A., Kim Y.B., Li X. et al.: Effects of light-emitting diodes on expression of phenylpropanoid biosynthetic genes and accumulation of phenylpropanoids in Fagopyrum tataricum sprouts. - J. Agr. Food Chem. 62: 4839-4845, 2014.

Vile D., Garnier E., Shipley B. et al.: Specific leaf area and dry matter content estimate thickness in laminar leaves. - Ann. Bot.-London 96: 1129-1136, 2005.

Wang H., Gu M., Cui J. et al.: Effects of light quality on $\mathrm{CO}_{2}$ assimilation, chlorophyll-fluorescence quenching, expression of Calvin cycle genes and carbohydrate accumulation in Cucumis sativus. - J. Photoch. Photobio. B 96: 30-37, 2009.

Wang J., Lu W., Tong Y., Yang Q.: Leaf morphology, photosynthetic performance, chlorophyll fluorescence, stomatal development of lettuce (Lactuca sativa L.) exposed to different ratios of red light to blue light. - Front. Plant Sci. 7: 250, 2016.

Wellburn A.R., Lichtenthaler H.: Formulae and program to determine total carotenoids and chlorophylls $a$ and $b$ of leaf extracts in different solvents. - In: Sybesma C. (ed.): Advances in Photosynthesis Research. Advances in Agricultural Biotechnology. Vol. 2. Pp. 9-12. Springer, Dordrecht 1984.

Wu M.C., Hou C.Y., Jiang C.M. et al.: A novel approach of LED light radiation improves the antioxidant activity of pea seedlings. - Food Chem. 101: 1753-1758, 2007.

Ye Z.P., Suggett D.J., Robakowski P., Kang H.J.: A mechanistic model for the photosynthesis-light response based on the photosynthetic electron transport of photosystem II in $\mathrm{C}_{3}$ and $\mathrm{C}_{4}$ species. - New Phytol. 199: 110-120, 2013.

Zhang Y., Kaiser E., Zhang Y. et al.: Red/blue light ratio strongly affects steady-state photosynthesis, but hardly affects photosynthetic induction in tomato (Solanum lycopersicum).Physiol. Plantarum 167: 144-158, 2019.

Zhen S., Haidekker M., van Iersel M.W.: Far-red light enhances photochemical efficiency in a wavelength-dependent manner. - Physiol. Plantarum 167: 21-33, 2019.

Zheng L., Ceusters J., Van Labeke M.-C.: Light quality affects light harvesting and carbon sequestration during the diel cycle of crassulacean acid metabolism in Phalaenopsis. Photosynth. Res. 141: 195-207, 2019.

Zheng L., Van Labeke M.-C.: Chrysanthemum morphology, photosynthetic efficiency and antioxidant capacity are differentially modified by light quality. - J. Plant Physiol. 213: 66-74, 2017.

Zhou W., Liu W., Yang Q.: Reducing nitrate content in lettuce by pre-harvest continuous light delivered by red and blue lightemitting diodes. - J. Plant Nutr. 36: 481-490, 2013.

Zoratti L., Karppinen K., Luengo Escobar A. et al.: Lightcontrolled flavonoid biosynthesis in fruits. - Front. Plant Sci. 5: 534, 2014.

(C) The authors. This is an open access article distributed under the terms of the Creative Commons BY-NC-ND Licence. 